\title{
DIALOGANDO COM OS ORDENAMENTOS BRASILEIROS VOLTADOS AO ENSINO DAS ARTES E DA MÚSICA
}

Sonia Regina Albano de Lima (UNESP)*

\begin{abstract}
RESUMO
O texto promove um diálogo da autora com os diversos ordenamentos legais voltados para o ensino das artes e da música, tanto na educação básica como no ensino superior. Trata-se de uma pesquisa documental-bibliográfica que traz uma reflexão da autora sob perspectivas diversas, entre elas a jurídica, a educacional e a institucional. Além da leitura dos ordenamentos, serviram de fundamentação teórica os textos de pesquisadores da área de educação e do ensino musical, considerando-se a importância da dialogicidade nos assuntos que envolvem a Educação e o ensino das Artes e da Música.
\end{abstract}

Palavras-chave: Legislação. Educação. Ensino artístico. Ensino musical.

\section{ABSTRACT \\ HAVING DIALOGUES WITH BRAZILIAN ORDINANCES RELATED TO THE TEACHING OF ARTS AND MUSIC}

The text promotes a dialogue between the author and the several legal ordinances turned to the teaching of arts and music, both in elementary education and in higher education. It is a matter of bibliographic research that brings the author reflections under several perspectives, among them the juridical, educational and institutional ones. In addition to the reading of the ordinances, the texts by researchers on the area of education and musical teaching served as theoretical foundation, taking into consideration the importance of the dialogicity in the matters which involve Education and the teaching of Arts and Music.

Keywords: Legislation. Education. Arts teaching. Musical teaching.

\section{RESUMEN}

\section{DIÁLOGO CON LOS ORDENAMIENTOS BRASILEÑOS VOLCADOS HACIA LA ENSEÑANZA DE ARTES PLÁSTICAS Y MÚSICA}

El texto promueve un diálogo entre la autora y los diversos ordenamientos legales volcados hacia la enseñanza de Artes Plásticas y Música, tanto en la educación básica como en la enseñanza superior. Se trata de una investigación bibliográfica que aporta la reflexión de la autora desde distintas perspectivas como la jurídica, la educativa y la institucional. Además de la lectura de los ordenamientos, tiene presente la fundamentación teórica de textos de investigadores en el área educativa, en el área de

* Pós-Doutorado em Música pelo Instituto de Artes da Universidade Estadual Paulista (IA-UNESP). Professora da Pós-Graduação em Música do Instituto de Artes da UNESP. E-mail: soniaalbano@uol.com.br 
la enseñanza de Música y considera la importancia de la dialogicidad en temas que implican la Educación y la enseñanza de Artes Plásticas y Música.

Palabras clave: Legislación. Educación. Enseñanza de plástica. Enseñanza de música.

\section{Introdução}

O texto aqui relatado analisa os ordenamentos legais voltados para o ensino da música e das artes em geral na educação básica e superior, tendo em vista que após a aprovação da Lei n ${ }^{0} 13.278$, de 02 de maio de 2016 (BRASIL, 2016a), e a implantação da Medida Provisória $\mathrm{n}^{\mathrm{o}} 746$, de 22 de setembro de 2016 (BRASIL, 2016b), está havendo, por parte dos professores de arte, um certo descontentamento no que se reporta à não obrigatoriedade do ensino artístico no ensino médio, e, também, certa apreensão dos educadores musicais quanto ao uso da polivalência nos processos de ensino/aprendizagem das artes, o que, em tempos anteriores, dificultou o aprendizado da linguagem musical por razões estruturais e infraestruturais a ele relacionadas.

Embora a Lei no 9.394/96 (BRASIL, 1996) - a Lei de Diretrizes e Bases da Educação Nacional (LDB) -, as Diretrizes Curriculares Nacionais (DCNs) (BRASIL, 2003), os Parâmetros Curriculares Nacionais - Arte (PCNs-Arte) (BRASIL, 1997) e a legislação complementar passassem a considerar a Arte como uma das áreas do conhecimento, nas escolas de educação básica as linguagens artísticas são ensinadas sob uma perspectiva polivalente, cumprindo determinações oriundas dos próprios ordenamentos pedagógicos. Podemos afirmar, com segurança, que a polivalência foi extinta dos cursos de formação dos professores de arte após a implantação das DCNs, contudo ela ainda é empregada pelos professores de arte da educação básica, trazendo alguns prejuízos para a docência musical, considerando-se a inadequação que se instalou entre a formação docente obtida nas licenciaturas da área e a real atuação deste professor em sala de aula.

Mesmo com a promulgação da Lei Ordinária ${ }^{\circ}$ 11.769 (BRASIL, 2008), de 18 de agosto de 2008, a maioria das escolas de educação básica, por razões múltiplas, tem priorizado o ensino das artes visuais e, em menor escala, das artes cênicas, uma vez que boa parte dos professores generalistas e licenciados de outras linguagens artísticas sentem-se um tanto despreparados para trabalhar contextos musicais, já que seus cursos de formação não privilegiaram o ensino desta linguagem. Em 2003, a professora Nair Pires, em artigo publicado na Revista da ABEM, já apontava para esta realidade:

O que se percebe é que os lugares que a música tem ocupado nos currículos escolares, lugares esses estabelecidos pela legislação educacional, não lhe têm conferido seu status de objeto de conhecimento. Apesar da música estar avançando ao longo dos anos dentro da hierarquia curricular, ela ainda não conquistou sua importância como conteúdo imprescindível à formação global do ser humano. Mesmo com a nova LDB/96, que considera a Arte como área de conhecimento, a música não tem garantida a sua presença nas escolas, visto que não existe a obrigatoriedade legal da presença de todas as formas artísticas nos currículos, cabendo a cada estabelecimento público, de acordo com seu interesse ou disponibilidade de professor, a escolha de qual ou mais linguagens artísticas 'quando e como serão abordadas na prática escolar'. (PIRES, 2003, p. 84, grifo nosso).

Devo esclarecer que a proposta de um ensino artístico polivalente, via de regra, atende de forma satisfatória às intenções pedagógicas veiculadas na legislação vigente, e tem sido uma prática recorrente nas produções artísticas atuais. Cada vez mais são produzidos espetáculos e apresentações artísticas que exigem um profissional, ou profissionais que saibam trabalhar com as Artes de forma interligada, contudo, por razões diversas, no ambiente educacional, questões e ações pedagógicas desta natureza são um tanto postergadas, principalmente quando relacionadas ao ensino da música.

A primeira razão para a adoção desse comportamento está centrada na relação díspare que existe entre as disciplinas que compõem a matriz curricular dos cursos de formação de docentes em música (Licenciaturas) e a atuação deste profissional em sala de aula. É mais do que sensato afirmar que ensinamos aquilo que aprendemos, contudo, tanto as licenciaturas em música quanto as licenciaturas em 
artes comportam uma base curricular voltada quase que integralmente para o aprendizado específico da sua área de formação. Seguindo este direcionamento, as inter-relações possíveis entre uma área e outra tornam-se cada vez mais complexas e um tanto improvisadas.

Acreditamos que a polivalência no ensino das artes só poderá se concretizar com eficiência e igualdade de condições, caso haja no ensino fundamental um docente para cada uma das linguagens artísticas trabalhando em conjunto com os demais licenciados da área, fato que ainda não se concretizou plenamente.

Em pesquisa realizada no ano de 2012, constatamos que a maioria das Licenciaturas em Artes conserva uma matriz curricular bastante tecnicista, voltada quase que exclusivamente para o aprendizado de uma única linguagem (LIMA et al, 2012). Essa realidade impede uma atuação eficiente do professor de artes na educação básica. As Licenciaturas em Música, por exemplo, comportam uma matriz curricular bastante voltada para o aprendizado da linguagem musical e das matérias pedagógicas. São raras as disciplinas que inter-relacionam a música com as demais linguagens artísticas, ainda que em sala de aula haja a necessidade de uma atuação pedagógica focada nas múltiplas linguagens. Também são limitadas as disciplinas que discutem a função social da música e sua importância no desenvolvimento integral do indivíduo. A não inclusão de disciplinas voltadas para o gerenciamento escolar, educação inclusiva, planificação curricular, elaboração de projetos e ações diretórias, entre outras, dificulta a formação de um professor de música mais participativo e atuante na educação e na sociedade. Também deve ser relatado que o número restrito de licenciados em música concorre para que licenciados vindos de outras licenciaturas em artes, professores generalistas e pedagogos assumam essa disciplina, apresentando, quase sempre, uma formação musical deficitária em relação aos licenciados em música.

Como se não bastasse, a infraestrutura que as instituições de educação básica dispõem para o ensino musical deixa muito a desejar. Em 2015, publiquei um texto demonstrando a importância de as escolas de ensino fundamental e médio contarem com estruturas arquitetônicas e infraestrutura ade- quadas para a efetivação de um ensino musical de qualidade. $\mathrm{O}$ capítulo apresentou um depoimento do maestro Samuel Kerr que corroborou minha argumentação, reafirmando a necessidade de uma reformulação desses espaços escolares a fim de abrigar atividades musicais diversas (LIMA, 2015).

Se os espaços escolares devem ser reformulados para que se promova um ensino musical de qualidade, o número reduzido de aulas semanais e a carga horária restrita destinada ao ensino das artes agrava mais a questão. Esperamos que nas escolas de ensino fundamental em tempo integral essa problemática seja sanada e que as aulas de artes tenham uma carga horária aumentada na matriz curricular e extracurricular. Entendemos que um trabalho efetivo com as múltiplas linguagens artísticas, mais intensamente com a música, requer práticas significavas capazes de promover a formação de sujeitos sensíveis, criativos e devidamente preparados para vivenciar experiências estéticas humanizadoras. Isso só será possível se a disciplina Artes tiver uma carga curricular maior e for considerada indispensável na formação dos alunos da educação básica.

O caráter utilitarista atribuído às práticas artísticas nas escolas de ensino fundamental e médio tem apontado para atividades circunscritas ao abrilhantamento de feiras, festas, comemorações, ou como elemento motivador para o entendimento de outras disciplinas. Tal atitude incita a prática de um ensino artístico superficial, que não atende o sentido maior desta modalidade de aprendizagem, e que, no mais das vezes, menospreza os saberes técnicos e teóricos indispensáveis para a sua real compreensão.

No campo musical, os educadores musicais têm tentado há vários anos trabalhar com a música como uma das formas de linguagem capaz de auxiliar beneficamente o ser humano no seu processo de desenvolvimento, já que um aprendizado que não cumpre esse objetivo torna-se vazio de sentido e função.

Curiosamente, deparei-me recentemente com uma publicação do regente e pianista Daniel Barenboim, reconhecendo a importância de as escolas de música difundirem um ensino musical capaz de transcender o puro tecnicismo, ainda que pese sua formação iminentemente performática: 
[...] nuestro sistema de educación actual olvida totalmente este campo [ensino de música], desde el parvulario hasta los últimos años de escuela. Incluso en las escuelas de música y en los conservatorios, la instrucción es altamente especializada y a menudo no está relacionada con el contenido real de la música y, por tanto, con su poder. La disponibilidad de grabaciones y películas de conciertos y óperas es inversamente proporcional a la escasez del conocimiento y la comprensión de la música prevaleciente en nuestra sociedad. El sistema actual de la educación pública es responsable del hecho de que una población sea capaz de escuchar prácticamente la pieza musical que quiera pero incapaz de concentrase plenamente en ella. La educación del oído es quizá mucho más importante de lo que podemos imaginar no sólo para el desarrollo de cada individuo sino también para el funcionamiento de la sociedad y, por tanto, también de los gobiernos. ' (BARENBOIM, 2008, p. 50-51).

Assim relatado, não nos parece infundada a apreensão dos educadores musicais à frente da promulgação dos últimos ordenamentos voltados para o ensino das artes em geral. Vejamos a alteração do $\S 6^{\circ}$ do art. 26 da Lei $n^{\circ} 9.394 / 96$ (LDB), implantada pela Lei $\mathrm{n}^{\circ} 13.278$ (BRASIL, 2016a), de 2 de maio de 2016, que reafirma a continuidade da polivalência no ensino das artes na educação básica:

$\S 6^{\circ}$ - As artes visuais, a dança, a música e o teatro são as linguagens que constituirão o componente curricular de que trata o $\S 2^{\circ}$ deste artigo.

Artigo $2^{\circ}$ - O prazo para que os sistemas de ensino implantem as mudanças decorrentes desta Lei, incluída a necessária e adequada formação dos respectivos professores em número suficiente para atuar na educação básica, é de cinco anos. (BRASIL, 2016a).

\footnotetext{
1 "Nosso sistema de educação atual esquece totalmente este campo [ensino de música], desde o jardim da infância até os últimos anos da escola. Inclusive, nas escolas de música e nos conservatórios a instrução é altamente especializada e frequentemente não está relacionada com o conteúdo real da música, ou seja, com o seu poder efetivo. A disponibilidade de gravações e filmes de concertos e óperas é inversamente proporcional à escassez de conhecimento e à compreensão da música que domina nossa sociedade. O sistema atual da educação pública é responsável pelo fato dos indivíduos escutarem a obra musical que mais lhes agrada, mas incapaz de se concentrarem nela efetivamente. A educação do ouvido é muito mais importante do que se pode imaginar, não só para o desenvolvimento do indivíduo, como também para o funcionamento da sociedade e, por consequência, dos governos."
}

Essa Lei Ordinária teve sua origem no Projeto de Lei do Senado Federal de no 337/2006, de autoria do Senador Roberto Saturnino, e, a partir de sua promulgação, pôs fim à vigência da Lei $\mathrm{n}^{0} 11.769$ (BRASIL, 2008), de 18 de agosto de 2008, que instituiu anteriormente a obrigatoriedade do ensino da música na educação básica, sem ser exclusivo. Essa lei ordinária trouxe novas esperanças aos educadores musicais no sentido de operacionalizar um ensino musical de qualidade para essas escolas.

Não se pode ignorar a luta incessante dos educadores musicais antes e depois da promulgação dessa lei, a fim de promover nos diversos níveis escolares e em suas diversas modalidades um ensino de música de qualidade, fosse ele polivalente ou não.

O Parecer CNE/CEB no 12/2013 (BRASIL, 2013) descreve de maneira sucinta a discussão promovida pelo Conselho Nacional de Educação com os diversos profissionais da área, a fim de transcender os desacertos pedagógicos oriundos do passado. O relatório da Conselheira Rita Gomes do Nascimento traz, além dessa discussão primária, um histórico breve da educação musical no Brasil e um relato de como a música pode integrar um projeto educativo nacional. No Mérito esta conselheira concluiu que a Lei $n^{\circ} 11.769 / 2008$ (brasil, 2008) é resultado de um processo permanente de luta histórica e socialmente construído por músicos e educadores na tentativa de revelar a importância da Música na formação integral dos estudantes:

É dessa forma, em um novo contexto de mobilização pelo reconhecimento da importância da Música na escola, compreendida como direito humano, promotora de cidadania e de maior qualidade social na educação, que se faz mister a aprovação de Diretrizes que orientem o tratamento a ser dado ao ensino de Música nas escolas da Educação Básica. Assim, não obstante a Lei $n^{\circ} 11.769 / 2008$ estabelecer a obrigatoriedade do ensino de Música, definindo 3 (três) anos letivos para que os sistemas de ensino atendam a esta determinação, ela não é autoaplicável, carecendo de regulamentação. Nesse sentido, o presente Parecer e o Projeto de Resolução anexo objetivam apresentar orientações que ajudem os sistemas de ensino a implementar o que determina a Lei, à Luz das Diretrizes Curriculares Nacionais Gerais para a Educação Básica e das Diretrizes específicas para suas etapas e modalidades. (BRASIL, 2013) 
A Resolução CNB/CEB no 2/2016 (BRASIL, 2016b), agregada ao Parecer CNB/CEB n ${ }^{\circ} 12$ (BRASIL, 2013), definiu as Diretrizes Nacionais para a operacionalização do ensino de Música na Educação Básica e só foi homologada em 10 de maio de 2016, no mesmo mês da promulgação da Lei ${ }^{\circ} 13.278$ (BRASIL, 2016), que alterou o artigo 26 da Lei 9.394/96 (BRASIL, 1996).

Apenas para conhecimento, o caput desse artigo revela que os currículos da educação infantil, do ensino fundamental e do ensino médio devem ter base nacional comum, a ser complementada em cada sistema de ensino e em cada estabelecimento escolar, por uma parte diversificada, exigida pelas características regionais e locais da sociedade, da cultura, da economia e dos educandos.

A Medida Provisória n. 746 (BRASIL, 2016b), de 22 de setembro de 2016, alterou o $\S 1^{\circ}$ do artigo 26 da Lei 9.394/96 (BRASIL, 1996) e determina que os currículos a que se refere o caput deste artigo devem abranger, obrigatoriamente, o estudo da língua portuguesa e da matemática, o conhecimento do mundo físico e natural e da realidade social e política, especialmente da República Federativa do Brasil, observado, na educação infantil, o disposto no art. 31; no ensino fundamental, o disposto no art. 32; e no ensino médio, o disposto no art. 36.

O artigo 31 da LDB (BRASIL, 1996) menciona, nos incisos de I a V, as regras comuns a serem observadas para o ensino infantil: avaliação sem objetivo de promoção para o acesso ao ensino fundamental; carga horária mínima anual de 800 horas; atendimento à criança que se estende de 4 horas diárias até 7 horas para a jornada integral, controle de frequência mínima de $60 \%$; expedição de documentação atestando o desenvolvimento e a aprendizagem da criança neste período.

$\mathrm{O}$ artigo 32 determina que o ensino fundamental na escola pública terá uma duração obrigatório de 9 anos, com início aos 6 anos de idade, e terá como objetivos: desenvolver o pleno domínio da leitura, da escrita e do cálculo; compreender o ambiente natural e social, o sistema político, a tecnologia, as artes e os valores que fundamentam a sociedade; desenvolver a capacidade de aprendizagem; fortalecer os vínculos de família, solidariedade humana e tolerância em que se assenta a vida social.

$\mathrm{O}$ artigo 36, referente ao ensino médio, foi bas- tante reformulado pela Medida Provisória n ${ }^{\circ}$ 746/16 (BRASIL, 2016b) e determina que o currículo a ser desenvolvido neste ciclo será composto pela Base Nacional Comum Curricular (BRASIL, 2016d) e por itinerários formativos específicos, a serem definidos pelos sistemas de ensino, com ênfase nas seguintes áreas de conhecimento ou de atuação profissional: linguagens; matemática; ciências da natureza; ciências humanas; e formação técnica e profissional.

O parágrafo $3^{\circ}$ desse artigo estipula que a organização das áreas abordadas será definida na Base Nacional Comum Curricular (BNCC) e feita de acordo com critérios estabelecidos em cada sistema de ensino. No parágrafo $8^{\circ}$ e $9^{\circ}$, a Medida Provisória estabeleceu em caráter obrigatório o estudo da língua inglesa, da língua portuguesa e matemática, não prescrevendo nos artigos subsequentes a obrigatoriedade do ensino das artes.

Nos parágrafos $2^{\circ}, 3^{\circ}$ e $5^{\circ}$ do art. 26 da LDB (BRASIL, 1996), ficou determinado que o ensino das artes, da educação física e da língua inglesa são componentes curriculares obrigatórios da educação infantil e do ensino fundamental. Em nenhum momento a MP relatou que a disciplina Artes será optativa ou obrigatória no ensino médio, fato que propagou diversas notas de repúdio das associações e dos pesquisadores ligados à área.

Não bastasse, o $\S 2^{\circ}$ do artigo 26 ressalta que o ensino da arte, especialmente em suas expressões regionais, constituirá componente curricular obrigatório da educação infantil e do ensino fundamental, de forma a promover o desenvolvimento cultural dos alunos. A menção não se estendeu para o ensino médio, o que se depreende mais uma vez que as artes não serão componentes curriculares obrigatórios do ensino médio e, provavelmente, também não serão componentes curriculares optativos, considerando-se o objetivo maior desta MP previsto, em parte, no artigo 36, quando afirma que a remodelação curricular imposta no artigo 36 da Lei 9.394/96 (BRASIL, 1996) insere itinerários formativos específicos em algumas áreas de conhecimento, visando uma formação técnica e profissional. Daí a certeza da ausência de um ensino artístico optativo no ensino médio.

É interessante observar que a Medida Provisória $n^{\circ}$ 746/2016 (BRASIL, 2016b) outorgou à Base 
Nacional Comum Curricular (BNCC) boa parte do poder decisório cabível ao ensino médio. Exemplo disso pode ser visualizado nos parágrafos $7^{\circ}$ e $10^{\circ}$ do artigo 26 da LDB (BRASIL, 1996); artigo 36 e parágrafos $3^{\circ}, 6^{\circ}$ e $15^{\circ} ; \S 3^{\circ}$ do artigo 44 e $\S 8^{\circ}$ do artigo 62, entre outros; entretanto, esta BNCC, há algum tempo, encontra-se paralisada.

O Prof. Dr. Marcos Garcia Neira, da Faculdade de Educação da Universidade de São Paulo (USP), especialista nomeado a partir de junho de 2015 para atuar na BNCC, em entrevista divulgada na Internet (NEIRA, 2016), ao se reportar ao trabalho realizado na BNCC, declara que durante um ano e meio um grupo grande de pessoas com trajetórias ligadas aos percursos curriculares e professores em atuação na educação básica trabalharam na elaboração de um documento que pudesse fundamentar, apoiar e ajudar as escolas do Brasil e os sistemas de ensino, porém, com as mudanças havidas no cenário político, a BNCC foi colocada de escanteio, inclusive foi acusada de ser um documento ideológico, um documento contaminado com certas visões de mundo.

Neira declara que esses argumentos devem ser relativizados, pois um texto construído por um grupo tão plural e com a participação de 12 milhões de contribuintes que fizeram suas críticas, suas análises, suas contribuições, suas sugestões, seria um material para estudo e um material de apoio, não só para o professor como também para a Secretaria de Educação. Vejamos o que relata esse especialista:

$\mathrm{O}$ documento passou por uma etapa de discussões nos seminários estaduais, em alguns desses seminários parte do documento relativo ao ensino médio simplesmente não foi discutida porque já se anunciava que viria uma reforma específica no ensino médio e, portanto, não seria necessário abordar o ensino médio [...] esse tal novo ensino médio, essa proposta de reforma, chega às pressas de afogadilho, atropelando todo o processo de discussão da base, inclusive essa etapa dos seminários estaduais. [...] Nós nos sentimos bastante constrangidos diante desses fatos, diante de uma ação autoritária, desconectada da realidade e sem a menor intenção de dialogar com os professores e professoras que estão na sala de aula. [...] Eu não tenho dúvidas que os efeitos deste novo ensino médio serão tremendamente terríveis, sobretudo nas camadas mais humildes da população. Segundo o texto, ficará a critério das instituições oferecer as áreas de aprofundamento. Nós sabemos que o Brasil enfrenta uma dificuldade muito grande para formar professores das áreas das ciências naturais e da matemática, então nós não temos dúvida que provavelmente a maior parte do ensino médio público atenderá às áreas de linguagens e de ciências humanas e no ensino privado nada mudará. $\mathrm{O}$ ensino privado continuará com esse ensino propedêutico, porque a lógica do ingresso no ensino superior continua sendo a mesma. Se não mexermos nesse processo, a tendência será essa. [...] como anunciou o professor G. Frigotto, nós teremos um retorno a reforma Capanema, lá nos anos 40, ou seja, nós teremos um ensino que segrega [...] Esse documento anuncia uma profissionalização que interrompe o percurso de acesso aos conhecimentos, que interrompe o percurso acadêmico, que interrompe o percurso escolar dos jovens. Então o documento, essa reforma, ela se anuncia bastante problemática para a realidade brasileira. (NEIRA, 2016)

Nesse mesmo documento, o BNCC não preteriu o ensino das artes na educação básica. Ele pensou as artes com formas diferenciadas de linguagem, diferentemente do que relata a MP nos artigos 26 $\S 1^{\circ}$ e 36 , inciso I e $\S 9^{\circ}$. Vejamos o tratamento conferido às Artes pela $\mathrm{BCNN}$ :

A utilização do termo 'linguagens', no plural, aponta para a abrangência do aprendizado na área de conhecimento, que recobre a linguagem verbal, musical, visual e corporal, e para a integração desses recursos expressivos na participação na vida social. $\mathrm{O}$ termo abrange também diferentes formas de experiências: estéticas, sensoriais, sensíveis, corporais, sonoras, sinestésicas, imagéticas, performativas. Cada prática de linguagem propicia ao sujeito uma dimensão de conhecimentos à qual ele não teria acesso de outro modo. Interagir em diversas línguas, manifestações artísticas e práticas corporais gera um tipo específico de conhecimento, possibilitando perceber o mundo e a si próprio/a de um modo singular. (BRASIL, 2016d, p. 86).

Contrariamente, a MP em questão reformula os artigos $26 \S 1^{\circ}$ e 36 , inciso I, e assim se reporta ao termo "linguagem".

Art $26-\S 1^{\circ}$

Os currículos que se refere o caput devem abranger obrigatoriamente o estudo da língua portuguesa e da matemática $[\ldots]$ 
Art. 36. O currículo do ensino médio será composto pela Base Nacional Comum Curricular e por itinerários formativos específicos, a serem definidos pelos sistemas de ensino, com ênfase nas seguintes áreas de conhecimento ou de atuação profissional:

I - linguagens;

$\S 9^{\circ}$ - O ensino da língua portuguesa e matemática será obrigatório nos três anos do ensino médio. (BRASIL, 2016b).

A Base Curricular, conforme dispõe a Lei $n^{\circ}$ 13.278/16 (BRASIL, 2016a), determinou que o componente curricular Arte engloba as 4 linguagens (Artes Visuais, Dança, Música e Teatro). Estabeleceu ainda seis dimensões para a construção do conhecimento em artes na escola (criação, crítica, estesia, expressão, fruição e reflexão) e o que seria específico de ser trabalhado em cada uma dessas linguagens (BRASIL, 2016d, p. 112-118), o que pressupõe o emprego da polivalência no ensino artístico, porém ministrado por educadores formados em cada uma dessas linguagens. Na introdução referente aos fundamentos do componente, o documento assim se expressa:

A trajetória do ensino e da aprendizagem das artes no Brasil é paralela à luta de profissionais comprometidos com a construção de políticas educacionais que subsidiam a qualificação das artes na escola. As lutas têm sido por um ‘saber de base, um saber específico', que reconheça as artes como conhecimentos imprescindíveis na formação plena do cidadão, rompendo com a atuação polivalente estabelecida pela LDB n. 5.692/71, que incluía a 'Educação Artística' no currículo como atividade complementar de outras disciplinas. A partir da década de 1990, a LDB n. 9394/96, os Parâmetros Curriculares Nacionais (PCNs) e as Diretrizes Curriculares Nacionais (DCN) reconhecem a especificidade das artes visuais, da dança, da música e do teatro como conhecimento, bem como a necessidade de formação específica para o professor. [...] O ensino e a aprendizagem dos conhecimentos artísticos na escola favorecem o respeito às diferenças e o diálogo intercultural, pluriétnico e plurilíngue [...] (BRASIL, 2016d, p. 112, grifo nosso).

O apelo tecnicista da MP, que contempla conteúdos curriculares para o ensino médio mais voltados para as exigências do mercado de trabalho, vai na contramão do que os pesquisadores ligados à área da educação têm propagado insistentemente, ou seja, desenvolver conteúdos curriculares centrados em formar um cidadão com valores éticos, estéticos, morais e mais sensibilizados pelas artes e pela cultura do seu pais. Em nenhum artigo a MP tratou de questões envolvendo a valorização das artes e da cultura.

Não se pode ignorar que se implantado um ensino médio de tempo integral justificar-se-ia a adoção de uma matriz curricular menos tecnicista com conteúdos curriculares ligado às Artes, uma vez que o acréscimo de tempo poderia ensejar a inserção de campos de conhecimento diversos, ações e atividades artísticas e culturais que aprimorariam o desenvolvimento cognitivo, afetivo e físico dos estudantes.

De maneira geral, a redação contida na MP traz à tona o descaso do legislador para com ordenamentos anteriores aprovados pelos órgãos competentes depois de longa discussão e estudos atuais que estão sendo explorados por profissionais da área.

No que se reporta ao ensino da música, professores, pesquisadores e associações como a Associação Brasileira de Educação Musical (ABEM) e a Associação Nacional de Pesquisa e Pós-Graduação em Música (ANPPOM) tiveram ordenamentos aprovados para tornar o ensino musical obrigatório, depois de uma longa discussão com parlamentares e o Conselho Nacional de Educação - Câmara de Educação Básica, sem contar outras questões que ainda estão sendo avaliadas pelos órgãos competentes, juntamente com os profissionais e educadores musicais. Tais dispositivos legais não devem ser menosprezados, principalmente a Resolução CNE/ CEB no 2/2016 (BRASIL, 2016c), que apresenta, após longa discussão, as Diretrizes Nacionais para a operacionalização do ensino de Música na Educação Básica.

A participação da comunidade musical e das associações de classe foram de suma importância na aprovação dessa Resolução. O Parecer CNE/CEB $n^{\circ} 12 / 2013$ (BRASIL, 2013), que fundamentou essa Resolução, foi bem elucidativo ao demonstrar a importância da inclusão do ensino musical na educação básica e aponta para a finalidade maior do ensino musical: o desenvolvimento integral do indivíduo sob uma perspectiva estética, psíquica, física e mental. Também não deve ser menosprezado o número de pesquisas que estão sendo direcionadas para discutir esta temática: 
Nas últimas décadas, pesquisas, em especial da neurociência, têm demonstrado a importância da música para o desenvolvimento humano, o funcionamento cerebral e a formação de comportamentos sociais. Considerado como um direito humano, o acesso ao estudo formal de Música atua de forma decisiva no processo de formação humana, afetando os processos de aprendizagem, inclusive os escolares. Assim, o estudo de Música é instrumental para modificar o funcionamento do cérebro em dimensões ligadas às aprendizagens dos conhecimentos formais e de outros fazeres do ser humano. A música mobiliza inúmeras áreas do cérebro, integrando-as de forma única em relação a outras atividades humanas. Segundo Gazzaniga (2008), existem ligações específicas entre o estudo de Música e a habilidade de manipular informação tanto na memória de trabalho (usada para pensar), como na memória de longa duração (usada para arquivar os conteúdos aprendidos, os métodos e a experiência). Nesse sentido, o estudo de Música impacta a aprendizagem de outras áreas do conhecimento, além de formar comportamentos de atenção que impulsionam e melhoram a cognição. Assim, a educação musical atua diretamente no cérebro, promovendo a atenção executiva, necessária para formar memórias de qualquer área do conhecimento formal e de suas metodologias. A prática musical também contribui para a interação social e formação de identidade cultural, fortalecendo os vínculos entre os membros de uma comunidade. Além disso, a música pode ter também um papel central no tratamento de doenças, melhorando o estado físico do organismo e facilitando a cura em muitos casos. $O$ cérebro humano é aparelhado para comunicação e uma dessas formas é a música, que transmite sentimentos e emoções que a própria fala não consegue traduzir em palavras. A prática musical também cria condições especiais de comunicação, tais como aquelas entre e com as pessoas com deficiência (surdas, cegas, mudas, com síndromes, com alterações em seu desenvolvimento, patologias, paralisia cerebral, entre outros). (BRASIL, 2013).

Mais antigos e com igual importância estão os Parâmetros Curriculares Nacionais: Arte (BRASIL: MEC/SEF, 1997, v. 6) e o Parecer CNE/CES $n^{\circ} 195 / 2003$, aprovado em 04 de agosto de 2003, publicado no Diário Oficial da União (DOU) em 12 de fevereiro de 2004, seção 1, p. 14, que institui as Diretrizes Curriculares Nacionais dos cursos de Graduação em Música, Dança, Teatro e Design, conferindo às Artes uma posição de destaque cog- nitivo na formação do conhecimento (BRASIL, 2003).

Impor uma MP para definir os rumos do ensino médio pareceu-nos uma ação um tanto infundada, considerando-se que os ordenamentos aqui relatados foram aprovados depois de uma longa discussão entre seus pares.

O pesquisador em Ciências da Educação, Prof. Dr. Anderson Araújo-Oliveira, em artigo publicado no ano de 2008 (ARAÚJO-OLIVEIRA, 2008), define, com acertabilidade, o que ele considera como "intervenção educativa", o que de certa forma poderia se estender às atividades intervencionistas do Estado em matéria referente à Educação, já que esta área de conhecimento tem priorizado, nos últimos anos, estudos pormenorizados do que vem a ser uma prática pedagógica e como ela se consolida frente à sua natureza multidimensional, considerando-se que ela é composta de várias dimensões que interagem mutuamente para permitir ao docente adaptar-se à situação profissional e gerir, conjuntamente com os alunos, as aprendizagens destes e a conduta da classe.

Para esse autor, a prática pedagógica consolida-se como uma atividade profissional situada, orientada por fins e pelas normas de um grupo profissional; engloba ao mesmo tempo as atividades com os alunos, mas também o trabalho coletivo e individual fora da classe; é multidimensional; não se limita às ações perceptíveis, mas comporta também as escolhas, as tomadas de decisões e os significados dados pelo professor a suas próprias ações; é a atividade profissional do professor antes, durante e depois da sua ação em classe (ARAÚJO-OLIVEIRA, 2008).

Diante desse entendimento, presume-se que uma intervenção educativa de qualquer natureza deve priorizar essas relações múltiplas e complexas, principalmente no que diz respeito à criação de ordenamentos para a área. Se a consulta às bases parece desnecessária a esses legisladores, ela é de extrema importância para o bom andamento da Educação, daí a importância de uma conceituação do termo "intervenção educativa":

Definimos a intervenção educativa como o conjunto das ações sistematizadas postas por pessoas designadas, fundamentadas e legitimadas para alcançar, num contexto institucionalmente específico, os objetivos 
educativos socialmente determinados, colocando em evidência as condições mais adequadas possíveis para favorecer a mise en oeuvre pelos alunos dos processos de aprendizagens adequados. (LENOIR; HASNI; LEBRUN, 2008, p. 31).

No que se reporta às práticas artístico-pedagógicas realizadas na educação básica, entendemos que afastar os estudantes de atividades artísticas que auxiliam a criatividade, a reflexão, a sensibilidade, o contato dos indivíduos com sua própria subjetividade, transformando-os em seres mais saudáveis emocionalmente e intelectualmente, seria negar o sentido maior da Educação Artística e da própria Educação.

Não seria exagero pensar que se não houver um diálogo conjunto das políticas públicas com a sociedade, os professores de artes, as instituições de ensino e as associações de classe, com certeza as Artes serão disciplinas minimizadas nas escolas de educação básica, considerando-se que dia a dia a Educação tem priorizado um ensino restrito à eficácia técnica em todos os campos do saber. É importante relembrar a fala do filósofo e educador Antonio Joaquim Severino quando afirma que o ensino deve estar à frente de uma formação puramente técnico-científica:

Nenhum profissional será, efetivamente em sua prática histórica, apenas um técnico; ele será necessariamente um sujeito interpelado pela história, pela sociedade, pela cultura e pela humanidade, devendo dar-lhes respostas que vão muito além de seu desempenho puramente operacional no âmbito da produção. (SEVERINO, 2011, p. 16).

Se essa tendência pedagógica se estender no ensino, em alguns anos as Licenciaturas em Artes serão reduzidas, principalmente as Licenciaturas em Música, pois não haverá mercado de trabalho para seus egressos e, nesses casos, a educação básica tenderá a indicar professores sem uma formação específica e significativa, o que representa um retrocesso e um desrespeito com os estudantes, a sociedade, os professores e a área como um todo. Diante dessa realidade, os trabalhos da BNCC devem continuar para que a Educação Brasileira possa caminhar de forma saudável e próspera.

As notas de repúdio presentes na mídia por parte de todas as associações e profissionais ligados ao ensino artístico, além da petição que tentou impedir a aprovação desta MP (AVAAZ, 2016), denotam o quão arbitrário será nortear o ensino médio a partir de uma Medida Provisória.

O Prof. Dr Marcos Garcia Neira, em entrevista, retrata o seu descontentamento com este ordenamento. Ele não contradiz a importância de uma reformulação do ensino médio, que, segundo sua perspectiva, é conteudista e propedêutica por excelência e, basicamente, não tem sido mais do que uma ponte para o ingresso de alguns setores da sociedade na Universidade:

[...] ninguém esperava que uma proposta viesse com essa cara, com esse teor e que apresentasse vários pontos que, no meu entendimento, precisam ser rapidamente revogados.[...] essa discussão tem que ser mais ampla, com maior participação da sociedade, sobretudo daqueles setores diretamente envolvidos que são os setores ligados ao magistério, setores ligados aos alunos ou jovens (já que vivemos em uma época em que os jovens se fizeram ouvir - então, precisamos ouvir o que eles pensam a respeito da própria educação que está sendo oferecida), bem como aquelas parcelas da sociedade que deverão receber diretamente os egressos do ensino médio, ou seja, os campos de atuação profissional, o ensino superior e uma série de outras instâncias. Então acho que uma coisa é a necessidade de se repensar o ensino médio e outra coisa é a cara dessa medida provisória. (NEIRA, 2016).

A falta de diálogo presente nessa Medida foi apontada pelo especialista ao afirmar: “[...] é algo que vem de cima para baixo, é algo que foi gestado por um grupo muito pequeno, com quais intenções ninguém sabe, e que vai trazer um impacto muito grande para as escolas, para a vidas das pessoas já a partir do ano que vem" (NEIRA, 2016). Também relatou que da forma como vai ser trabalhado o ensino médio, o aprofundamento em determinadas áreas não será possível:

Isso é um pouco problemático porque obriga uma mudança curricular que retira o direito de uma grande parcela da população acessar, interagir, conhecer e ampliar o seu universo de conhecimentos. [...] com essas mudanças aquele jovem ou adulto que escolher a área de linguagens e tiver uma carga horária reduzida ou nenhum contato com as outras áreas e com os conhecimentos que vem historicamente 
caracterizando a área, a possibilidade dele compreender o mundo e dele poder fazer uma intervenção mais qualificada e crítica com muitos, será bastante reduzida. (NEIRA, 2016).

Não foi esquecido, por parte do entrevistado, a questão da formação de professores e a falta de obrigatoriedade do ensino de psicologia, filosofia, aliado ao ensino das artes e da educação física:

[...] eu vejo com muitas ressalvas esse documento, essa possibilidade de mudança, que eles estão chamando de novo ensino médio [...] todos os grupos sociais, todos os grupos humanos, ao longo da história vem produzindo essas formas de expressão da cultura, então, retirar dos estudantes a possibilidade de conhecer isso, retirar dos estudantes a possibilidade de reconstruir, retirar dos estudantes a possibilidade de interagir com esses saberes tão importantes e diversificados, significa, ao mesmo tempo, amputar a possibilidade de uma participação cidadã mais efetiva. São conhecimentos que ganharam relevância nos últimos 50 anos, são conhecimentos que nos constituem enquanto sujeitos, são conhecimentos que nos permitem apurar o nosso olhar crítico para a sociedade. (NEIRA, 2016).

A Associação Brasileira de Etnomusicologia (2016), entre outras, manifestou seu repúdio a esse ordenamento declarando:

Esta postura autoritária e desrespeitosa vai na contramão do princípio de 'gestão democrática' que representou uma das maiores conquistas de nossa história recente e está garantido no atual Plano Nacional de Educação-2014/2024 (Lei n ${ }^{\circ} 13.005$, de 25 de junho de 2014). A ABET participou com entusiasmo da elaboração do texto preliminar da Base Curricular Nacional Comum para o Ensino Básico num trabalho coletivo que se deu por meio de um amplo diálogo/ debate envolvendo gestores públicos, profissionais da educação, associações acadêmicas e a sociedade em geral. (ABET, nota de repúdio).

Da mesma maneira, o Presidente da Associação Brasileira de Educação Musical, Prof. Dr. Luis Ricardo Silva Queiroz, manifestou-se contrário a essa MP:

A sociedade brasileira tem assumido, cada vez mais, a educação básica como um projeto de nação, com a consciência de que, mais do que transmitir conhecimentos de campos legitimados a partir de tendências pragmáticas de uma educação exclusivamente tecni- cista e de cunho neoliberal - tendências essas dominantes no Brasil até o início dos anos 2000 -é preciso uma educação que vise formar fundamentalmente seres humanos. Seres que, além de conhecimentos de sintaxe linguística, de fórmulas matemáticas e de elementos do mundo físico e natural (reconhecendo que esses saberes também são fundamentais para vida), precisam para sua formação plena como humanos de dimensões que perpassam pelas artes, pela filosofia, pela sociologia, pela educação física e por todos os conhecimentos e saberes vinculados às múltiplas faces que configuram a formação do indivíduo. (QUEIROZ, 2016).

Muitas outras notas de repúdio foram publicadas nas redes sociais, inclusive a que redigi na qualidade de Presidente da ANPPOM (LIMA, 2016).

Um fato que nos causou estranheza foi a reportagem publicada na Revista ISTOÉ (UMA REVOLUÇÃO..., 2016), que contrariando os prognósticos negativos divulgados pelas associações e pesquisadores da área, traz uma matéria ampla relatando os benefícios advindos da MP. A reportagem relata que este ordenamento se apresenta como uma das maiores mudanças na educação nacional dos últimos 20 anos, desde a instauração da Lei ${ }^{\circ}$ 9.394/96 (BRASIL, 1996):

Além das disciplinas obrigatórias, a ideia é possibilitar ao aluno escolher se aprofundar nas áreas com as quais têm mais afinidade, tornando, assim, o estudo mais atrativo. Há também a preocupação de ampliar o ensino integral. Segundo o presidente Michel Temer, um novo tipo de escola vai surgir a partir desse projeto. 'Os jovens poderão escolher o currículo mais adaptado à vocação. Serão oferecidas opções e não mais imposições', disse. [...] A maneira como a proposta foi colocada, como uma medida provisória, dividiu opiniões entre os especialistas. Para muitos deles, deveria haver mais discussão com representantes de entidades educacionais. O governo se justifica dizendo que a mudança é colocada em caráter de urgência porque não se pode mais esperar [...] Na opinião do presidente do Conselho Nacional de Secretários de Educação, Eduardo Deschamps, as mudanças devem acontecer de maneira gradativa. A adaptação das instituições ao período integral, que já estava em curso, dependerá da capacidade financeira de cada mantenedor. 'Isso se dará dentro da realidade de cada rede, mas algumas receberão um aporte financeiro da União', diz. 'A flexibilização curricular terá mais etapas a cumprir.' Uma base co- 
mum de disciplinas obrigatórias será definida e terá de passar pela regulamentação do Conselho Nacional de Educação e dos conselhos estaduais. Após esse período, as escolas terão, segundo ele, um período de seis meses para se adaptar às mudanças propostas. (UMA REVOLUÇÃO..., 2016).

Confirma-se nessa leitura o prognóstico de um ensino médio bastante técnico, a serviço de necessidades mercantilistas. Com certeza a ausência das Artes no ensino médio e a falta de um planejamento curricular objetivo e claro para as Artes na educação básica promoverá uma atuação docente bastante superficial. No que diz respeito ao ensino de música, inúmeros exemplos demonstram a acertabilidade dessa afirmativa.

Em contraposição à reportagem da Revista ISTOÉ, segue a reportagem de Paulo Blikstein (2016), na Veja.com de 23 de setembro de 2016, intitulada "Ensino flexível, mas chances iguais", onde admite que a reforma do ensino médio pretendida pelo governo deve respeitar a individualidade do aluno, guiar-se pela absoluta igualdade de oportunidades e oferecer conteúdos relevantes e atuais:

A intenção de reformar o ensino médio é excelente. Mas a melhor reforma será aquela que respeita a individualidade do aluno, não o vê como um mero insumo de produção industrial, tem como norte a igualdade de oportunidades e oferece conteúdos e métodos de ensino relevantes e atuais. Uma combinação difícil, mas de forma nenhuma impossível, principalmente para um país criativo como o Brasil. (BLIKSTEIN, 2016).

Muito ainda haveria a ser dito com relação aos ordenamentos voltados para o ensino das artes, mais diretamente para o ensino musical, no entanto, o que nos parece mais temerário é reconhecermos, por parte do governo, um certo desrespeito e até mesmo um desconhecimento das ações e medidas educacionais tomadas pelos educadores e associações de classe. A subserviência do Estado frente às demandas econômicas e financeiras ainda determinam o futuro da educação e, de modo algum, vislumbram o desenvolvimento integral do indivíduo, que é o objetivo maior do ensino em geral.

$\mathrm{O}$ trabalho do BNCC pareceu estar tomando esse direcionamento, mas como argumentou o especialista Neira, encontra-se um tanto marginalizado na condução desse trabalho. Esse documento finalizado poderia coordenar uma discussão ampla das propostas educacionais com os envolvidos diretamente no desenvolvimento dos cursos de formação de docentes, promovendo subsídios para uma atuação mais eficaz dos professores na cadeia educacional; poderia subsidiar e acompanhar a elaboração de propostas curriculares específicas para cada curso de licenciatura com suficiente flexibilidade para promover as reformulações necessárias, além de instituir um programa permanente de formação e capacitação continuada dos docentes nas diversas áreas de conhecimento.

A bem da verdade, a falta de articulação e de um adequado equilíbrio entre os aspectos teóricos e práticos que envolvem a educação continuam a ser uma batalha não resolvida no sistema de ensino nacional brasileiro. Em texto publicado no ano de 2008, referente a uma comunicação que proferi em Marrakech (Marrocos), na Université Cadi Ayyad (LIMA, 2008), detive-me nesta temática relatando que os procedimentos educativos não podem se pautar em resultados de investigações quantitativas ou modelos importados de ação. Não existe uma relação mecânica entre o conhecimento do professor e a aprendizagem do aluno, ou entre a capacitação do professor e o rendimento escolar. Não há uma quantidade mensurável de aprendizagem em cada ano de estudo, nem um modelo único de ensino praticável em toda a nação. Hoje a escola não se define apenas como um espaço de produção de conhecimento. Ela também é um espaço de socialização, de cidadania, de congraçamento, de experiências a serem vivenciadas coletivamente. Da mesma forma, o conhecimento produzido em sala de aula não pode ser medido ou avaliado por critérios estatísticos, já que ele é resgatado sempre e na medida em que as nossas experiências de vida os tornam significativos, e na proporção direta do envolvimento afetivo e eficaz que foi disponibilizado pelo docente durante o processo de ensino. Trata-se de uma troca congenial e dialógica. Sendo assim, as informações na área educativa contêm inúmeras variantes, múltiplas especificidades e precisam ser analisadas criteriosamente.

Os interesses das políticas públicas, das instituições de ensino, da LDB, dos ordenamentos educacionais, da sociedade e do mercado de trabalho são distintos, portanto exigem um diálogo 
contínuo para uma perfeita adequação, inclusive com relação ao entrelaçamento das diversas áreas de conhecimento, entre elas situam-se as artes e a música. Se assim ocorresse, seria importante um diálogo permanente da sociedade com o Estado, numa parceria comprometida com os interesses dos cidadãos, desenvolvendo atitudes mais responsáveis e não tão partidárias às necessidades de uma política comprometida com interesses mercantilistas. Só então haveria o envolvimento coletivo da sociedade em prol de uma educação sadia.

Não basta uma ação isolada do Estado, ou das instituições de ensino, nem mesmo a ação de uma docente capacitado profissionalmente. Entendo uma falha abrigar nas instituições alunos com comprometimentos social, físico e psíquico sem propiciar o devido tratamento médico, psíquico e social a ele e aos seus familiares. Sistemas de avalição por parte dos órgãos fiscalizadores, ainda que necessários, também serão desprovidos de sentido se introduzidos de forma genérica e universal para todos os setores do ensino. Cada nível escolar contém suas especificidades. Reformas impostas por ordenamentos sem o devido diálogo com a Educação e a Sociedade não atingirão seus objetivos se as instituições de ensino não souberem abrigar, integrar e transcender o cotidiano sociocultural obtido pelos alunos fora dos muros escolares. Da mesma maneira, um ensino que não valoriza os seus padrões culturais está fadado ao insucesso. A nossa educação não pode e não deve se esquecer que, antes de tudo, ela é brasileira. O conhecimento verdadeiro não menospreza sua história, sua cultura, as tradições. Não existe um modelo de sociedade perfeito, um modelo de reforma de ensino, mas uma sociedade para determinado povo e uma reforma de ensino adequada para determinada nação. Uma reforma de ensino assim pensada traz fluência na sua execução, benefícios para os sujeitos implicados e não se transforma em uma prática fragmentada de agir. Como relata a educadora Maria Cândida Moraes
[...] como educadores, necessitamos cuidar da formação integral do aprendiz para que ele possa aprender a pensar de uma maneira mais global, a refletir, a criar com autonomia soluções para problemas, estimulando o pleno desenvolvimento de sua inteligência, na qual compreendemos também estar incluída a sua inteligência emocional. Em resumo, temos que estar voltados para a sua formação integral, para o desenvolvimento de suas inteligências, de seu pensamento e de seu espírito, mediante o desenvolvimento da capacidade de problematização e articulação de conhecimentos, reconhecendo, sobretudo, a inscrição corporal do conhecimento, na qual a emoção apresenta um papel relevante como potencializadora de ações e reflexões inerentes aos processos de aprendizagem. (MORAES 1997 apud LIMA, 2008, p. 197-198).

Como relatam Ivani Fazenda e Severino (2001), a Educação é uma prática dialógica que envolve o exercício da parceria e da troca. Essa troca nasce de projetos detalhados e dissecados de estudo e de vida, projetos oriundos de incentivos comuns aos estudos e à pesquisa que se desenvolvem na forma como se compartilham falas, textos, espaços, tempos, práticas e teorias. Complementaria essa fala alertando para a profunda necessidade de as políticas públicas desenvolverem com a sociedade e a educação a arte de dialogar.

O presente texto foi concluído antes da aprovação da Lei ${ }^{\circ} 13.415$, de 16 de fevereiro de 2017, ordenamento que converteu a Medida Provisória n. 746, de 22 de setembro de 2016 em lei. Esse novo ordenamento alterou parte da Medida Provisória, proclamando no $\S 2^{\circ}$ do artigo 35-A, que a Base Nacional Comum Curricular referente ao ensino médio incluirá obrigatoriamente estudos e práticas de educação física, arte, sociologia e filosofia (BRASIL, 2017). Tal fato modifica em parte o destino do ensino das artes na educação média, contudo, é bom ressaltar que as Artes novamente não serão consideradas disciplinas a serem ministradas neste nível de ensino e sim práticas ou estudo, fato que vislumbra uma nova discussão.

\section{REFERÊNCIAS}

ARAÚJO-OLIVEIRA, Anderson. O olhar da pesquisa em educação sobre a multidimensionalidade subjacentes às práticas pedagógicas. In: FAZENDA, Ivani (Org.). O que é interdisciplinaridade. São Paulo: Cortez, 2008. p. 53-64. 
ASSOCIAÇÃO BRASILEIRA DE ETNOMUSICOLOGIA. Nota de repúdio à Medida Provisório nº 746. 2016. Disponível em: <http://abetmusica.org.br/conteudo.php?\&sys=noticias>. Acesso em: 21 nov. 2016.

BARENBOIM, Daniel. El sonido es vida. El poder de la Música. Bogotá: Grupo Editorial Norma, 2008.

BLIKSTEIN, Paulo. Ensino flexível mas chances iguais. Veja.com, São Paulo, 23 set. 2016. Disponível em: $<$ http:// veja.abril.com.br/complemento/pagina-aberta/ensino-flexivel-mas-chances-iguais.html>. Acesso em: 13 nov. 2016.

BRASIL. Presidência da República. Lei no 9.394, de 20 de dezembro de 1996. Estabelece as diretrizes e bases da educação nacional. Brasília, DF, 1996. Disponível em: <https:/www.planalto.gov.br/ccivil_03/Leis/L9394.htm>. Acesso em: 14 nov. 2016.

Ministério da Educação. Secretaria de Educação Fundamental. Parâmetros Curriculares Nacionais: Arte. v. 6. Brasília, DF: MEC/SEF, 1997.

Ministério da Educação. Parecer CNE/CES n 195, aprovado em 05 de agosto de 2003. Institui as Diretrizes Curriculares Nacionais dos Cursos de Graduação em Música, Dança, Teatro e Design. Brasília, DF, 2003. Publicado no DOU em 12 de fevereiro de 2004, seção 1, p. 14.

Presidência da República. Lei no 11.769, de 18 de agosto de 2008. Altera a Lei n. 9.394, de 20 de dezembro de 1996, Lei de Diretrizes e Bases da Educação, para dispor sobre a obrigatoriedade do ensino de música na educação básica. Brasília, DF, 2008. Disponível em: <http://www.planalto.gov.br/ccivil_03/_Ato2007-2010/2008/ lei/L11769.htm>. Acesso em: 14 nov. 2016.

. Ministério da Educação. Parecer CNE/CEB n 12, de 04 de dezembro de 2013. Discute as Diretrizes Nacionais para a operacionalização do ensino de Música na Educação Básica. Brasília, DF, 2013. Disponível em: <http:// portal.mec.gov.br/index.php?option=com_docman\&view=download\&alias=14875-pceb012-13\&Itemid=30192>. Acesso em: 14 nov. 2016.

Presidência da República. Lei no 13.278, de 2 de maio de 2016. Altera o $§ 6^{\circ}$ do art. 26 da Lei n. 9.394, de 20 de dezembro de 1996, que fixa as diretrizes e bases da educação nacional, referente ao ensino de arte. Brasília, DF, 2016a. Disponível em: <http://www.planalto.gov.br/ccivil_03/_Ato2015-2018/2016/Lei/L13278.htm>. Acesso em: 14 nov. 2016.

Presidência da República. Medida Provisória no 746, de 22 de setembro de 2016. Institui a Política de Fomento à Implementação de Escolas de Ensino Médio em Tempo Integral, altera a Lei n. 9.394, de 20 de dezembro de 1996, que estabelece as diretrizes e bases da educação nacional, e a Lei n. 11.494, de 20 de junho de 2007, que regulamenta o Fundo de Manutenção e Desenvolvimento da Educação Básica e de valorização dos profissionais da educação e dá outras providências. Brasília, DF, 2016b. Disponível em: <http://www.planalto.gov. br/ccivil_03/_ato2015-2018/2016/Mpv/mpv746.htm>. Acesso em: 14 nov. 2016.

Ministério da Educação. Resolução CNE/CEB no 2, de 10 de maio de 2016. Define as Diretrizes Nacionais para a operacionalização do ensino de música na Educação Básica. Acesso em 15 de novembro de 2016. Brasília, DF, 2016c. Disponível em: <file://C:/Users/Sonia/Downloads/Res\%202-2016-CEB-DCNs\%20 operacionaliza $\% \mathrm{C} 3 \% \mathrm{~A} 7 \% \mathrm{C} 3 \% \mathrm{~A} 30-$ ensino-M\%C3\%BAsica-Educa $\% \mathrm{C} 3 \% \mathrm{~A} 7 \% \mathrm{C} 3 \% \mathrm{~A} 3 \mathrm{o} \% 20 \mathrm{~B} \% \mathrm{C} 3 \% \mathrm{~A} 1$ sica $\% 20$ (2).pdf>. Acesso em: 20 nov. 2016.

Ministério da Educação. Base Nacional Comum Curricular. 2a versão revista, abril de 2016. Proposta Preliminar. Brasília, DF, 2016d. Disponível em: <http://movimentopelabase.org.br/wp-content/uploads/2016/05/ BNCC-BOOK-WEB.pdf>. Acesso em: 28 set. 2016.

Presidência da República. Lei n. 13.415, de 16 de fevereiro de 2017. Altera as Leis nos 9.394, de 20 de dezembro de 1996, que estabelece as diretrizes e bases da educação nacional, e 11.494, de 20 de junho 2007, que regulamenta o Fundo de Manutenção e Desenvolvimento da Educação Básica e de Valorização dos Profissionais da Educação, a Consolidação das Leis do Trabalho - CLT, aprovada pelo Decreto-Lei no 5.452, de 1o de maio de 1943, e o Decreto-Lei no 236, de 28 de fevereiro de 1967; revoga a Lei no11.161, de 5 de agosto de 2005; e institui a Política de Fomento à Implementação de Escolas de Ensino Médio em Tempo Integral.

FAZENDA, Ivani C. A; SEVERINO, Antonio H. (Org.). Conhecimento, pesquisa e educação. Campinas, SP: Papirus, 2001.

LENOIR, Yves; HASNI, Abdelkrim; LEBRUN, Johanne. Resultados de vinte anos de pesquisa: a importância atribuída às disciplinas escolares que objetivam a construção da realidade humana, social e natural no Ensino Pri- 
mário da Província de Québec - Canadá. In: O que é interdisciplinaridade? FAZENDA, Ivani (Org.). São Paulo: Cortez, 2008. p. 29-52.

LIMA, Sonia R. A. Nota pública da Presidência da ANPPOM sobre a MP. N. 746/2016. 2016. Disponível em: $<$ http://www.anppom.com.br/associacao/documentos. 2016>. Acesso em: 12 dez. 2016.

. Mais reflexão, menos informação! In: FAZENDA, Ivani (Org.). O que é interdisciplinaridade. São Paulo:

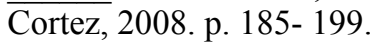

Os ordenamentos educacionais e sua real aplicabilidade. In: BAPTISTA, Ana Maria Haddad. Et al (Org.). Artes, ciências e educação. São Paulo: BT Acadêmica, 2015. p. 125-151.

LIMA, Sonia R. A. Et al (Org.). Arte, cultura e educação na formação de docentes: ilusão ou realidade? São Paulo: Som, 2012.

NEIRA, Marcos Garcia. Entrevista. 2016. Disponível em: <https://m.facebook.com/story.php?story fbid=1512613272098212\&substory_index=66\&id=100000486629296>. Acesso em: 02 out. 2016.

AVAAZ. Congresso Nacional: impeça a aprovação da Medida Provisória que reformula o Ensino Médio. 2016. Disponível em: <https://secure.avaaz.org/po/petition/congresso_nacional_Impedir_a_aprovacao_da_medida_provisoria_que_reformula_o_ensino_medio/?kGNZhlb>. Acesso em: 20 nov. 2016.

PIRES, Nair. A identidade das licenciaturas na área de música: multiplicidade e hierarquia. Revista da ABEM, Porto Alegre, n. 9, p. 81-88, set. 2003.

QUEIROZ, Luis Ricardo Silva. Nota pública da ABEM sobre a M. P. n. 746, que altera o ensino médio. 2016. Disponível em: <http://faeb.com.br/admin/upload/files/Notas\%20de\%20Repudio\%20em\%20PDF/Nota\%20 p \%C3\%BAblica\%20da\%20ABEM\%20sobre\%20a\%20Medida\%20Provis $\%$ C3\%B3ria $\%$ C2\%A0n\%C2\%BA $\% 20$ 746\%20que\%20altera\%20o\%20ensino\%20M\%C3\%A9dio.pdf>. Acesso em: 20 nov. 2016.

SEVERINO, Antônio Joaquim. Filosofia na formação universitária. São Paulo: Arte-Livros, 2011.

UMA REVOLUÇÃO no Ensino Médio. Istoé, São Paulo, n. 2442, seção Comportamento, 23 set. 2016. Disponível em: <http://istoe.com.br/uma-revolucao-no-ensino-medio/>. Acesso em: 22 nov. 2016.

Recebido em: 30/12/2016

Aprovado em: 10/03/2017 